University of Wollongong

Research Online

Faculty of Social Sciences - Papers (Archive) Faculty of Arts, Social Sciences \& Humanities

2016

Defining problematic pharmaceutical opioid use among people prescribed opioids for chronic noncancer pain: do different measures identify the same patients?

Gabrielle Campbell

University of New South Wales

Raimondo Bruno

University of Tasmania

Nicholas Lintzeris

University of Sydney

Milton Cohen

University of New South Wales

Suzanne Nielsen

University of New South Wales

See next page for additional authors

Follow this and additional works at: https://ro.uow.edu.au/sspapers

Part of the Education Commons, and the Social and Behavioral Sciences Commons

Research Online is the open access institutional repository for the University of Wollongong. For further information contact the UOW Library: research-pubs@uow.edu.au 


\title{
Defining problematic pharmaceutical opioid use among people prescribed opioids for chronic noncancer pain: do different measures identify the same patients?
}

\begin{abstract}
The International Classification of Diseases (ICD) and the Diagnostic and Statistical Manual (DSM) are routinely used in diagnosing illicit substance use disorders, but for people taking prescribed opioids they remain controversial. In pain medicine, the concept of "Addiction" is preferred with reduced emphasis on tolerance and withdrawal. This article examines the prevalence and characteristics of pharmaceutical opioid dependence/disorder according to ICD, DSM, and the pain medicine concept of "Addiction," among chronic noncancer pain (CNCP) patients prescribed opioids. In the current study, we used data from a national sample of 1134 people prescribed opioids for CNCP. Past 12-month "Addiction" (based on Pain Medicine definition), DSM, and ICD dependence definitions were assessed using the Composite International Diagnostic Interview. Twenty-four percent of the cohort met the criteria for "Addiction," 18\% for DSM-5 use disorder and 19\% for ICD-11 dependence. There was "substantial" concordance between "Addiction" and both DSM-5 use disorder and ICD-11 dependence, although concordance was much greater with ICD-11 dependence (kappa $=0.63$ and 0.79 , respectively). Participants meeting the criteria for "Addiction" only were older, less likely to engage in nonadherent behaviours, self-reported fewer problems or concerns with their medication, and had lower rates of psychological distress than those who also met the DSM-5 and ICD-11 criteria. The definition of "Addiction" captures a larger group of patients than other classification systems and includes people with fewer "risk" behaviours. Despite removal of tolerance and withdrawal for prescribed opioid use for DSM-5, we found that "Addiction" was more closely related to an ICD-11 diagnosis of pharmaceutical opioid dependence.
\end{abstract}

\section{Keywords}

among, opioid, patients?, pharmaceutical, identify, problematic, defining, do, pain:, noncancer, chronic, opioids, same, prescribed, measures, different, people

\section{Disciplines \\ Education | Social and Behavioral Sciences}

\section{Publication Details}

Campbell, G., Bruno, R., Lintzeris, N., Cohen, M., Nielsen, S., Hall, W., Larance, B., Mattick, R. P., Blyth, F., Farrell, M. \& Degenhardt, L. (2016). Defining problematic pharmaceutical opioid use among people prescribed opioids for chronic noncancer pain: do different measures identify the same patients?. Pain, 157 (7), 1489-1498.

\section{Authors}

Gabrielle Campbell, Raimondo Bruno, Nicholas Lintzeris, Milton Cohen, Suzanne Nielsen, Wayne Hall, Briony K. Larance, Richard P. Mattick, Fiona Blyth, Michael P. Farrell, and Louisa Degenhardt 
Defining problematic pharmaceutical opioid use among people prescribed opioids for chronic noncancer pain: do different measures identify the same patients?

Gabrielle Campbell ${ }^{1}$, Raimondo Bruno ${ }^{2}$, Nick Lintzeris ${ }^{3,4}$, Milton Cohen ${ }^{5}$, Suzanne Nielsen ${ }^{1}$, Wayne Hall $^{6,7}$, Briony Larance ${ }^{1}$, Richard P. Mattick ${ }^{1}$, Fiona Blyth ${ }^{3}$, Michael Farrell ${ }^{1}$ and Louisa Degenhardtt ${ }^{1,8,9,10}$.

1. National Drug and Alcohol Research Centre, UNSW, Australia

2. School of Medicine, University of Tasmania, Australia

3. Sydney Medical School, Sydney University, Australia

4. The Langton Centre, South East Sydney Local Health District (SESLHD) Drug and Alcohol Services, Australia

5. St Vincent's Clinical School, UNSW Medicine, UNSW Australia

6. Centre for Youth Substance Abuse Research, University of Queensland, AUSTRALIA

7. National Addiction Centre, Kings College, London ENGLAND

8. School of Population and Global Health, University of Melbourne, Australia

9. Murdoch Children's Research Institute, AUSTRALIA

10. Department of Global Health, School of Public Health, University of Washington, USA

Key words: chronic non-cancer pain, opioids, addiction, dependence

\section{Abstract}

The International Classification of Diseases (ICD) and the Diagnostic and Statistical Manual (DSM) are routinely used in diagnosing illicit substance use disorders, but for people taking prescribed opioids they remain controversial. In pain medicine the concept of 'Addiction' is preferred with reduced emphasis on tolerance and withdrawal. This paper examines the prevalence and characteristics of pharmaceutical opioid dependence/disorder according to ICD, DSM and the pain medicine concept of 'Addiction', among chronic non-cancer pain (CNCP) patients prescribed opioids. In the current study we used data from a national sample of 1,134 people prescribed opioids for CNCP. Past 12 month 'Addiction' (based on Pain Medicine definition), DSM and ICD dependence definitions were 
assessed using the Composite International Diagnostic Interview.

Twenty-four percent of the cohort met criteria for 'Addiction', 18\% for DSM-5 use disorder and 19\% for ICD-11 dependence. There was 'substantial' concordance between 'Addiction' and both DSM-5 use disorder and ICD-11 dependence, though concordance was much greater with ICD-11 dependence (kappa's 0.63, 0.79, respectively). Participants meeting criteria for 'Addiction' only were older, less likely to engage in non-adherent behaviours, self-reported fewer problems or concerns with their medication, and had lower rates of psychological distress than those who also met DSM-5 and ICD-11 criteria.

The definition of 'Addiction' captures a larger group of patients than other classification systems, and includes people with fewer 'risk' behaviours. Despite removal of tolerance and withdrawal for prescribed opioid use for DSM-5, we found that 'Addiction' was more closely related to an ICD-11 diagnosis of pharmaceutical opioid dependence.

\section{Introduction}

There has been increasing concern about risks for problematic use of pharmaceutical opioids in people prescribed opioids for chronic non-cancer pain (CNCP) [7]. Understanding the nature and extent of this issue has been limited due to inconsistency in how problematic opioid use is defined $[28 ; 29 ; 36]$.

The International Classification of Diseases (ICD) and the Diagnostic and Statistical Manual (DSM) are commonly used in illicit substance use research and clinical practice (See Appendix A for specific operationalisations, available online as Supplemental Digital Content at http://links.Iww.com/PAIN/A251). In the field of pain medicine, however, they remain controversial [3; 29]; tolerance and withdrawal are considered normal physiological consequences of long-term opioid use rather than indicators of problems. Other features are emphasised [21].

'Addiction', as defined by the American Academy of Pain Medicine, American Pain Society and American Society of Addiction Medicine [28] is behaviour including one or more of the following, 
impaired control over drug use, compulsive use, continued use despite harm, and cravings. A recent consensus statement from the Analgesic, Anaesthetic, and Addiction Clinical Trial Translations, Innovations, Opportunities, and Networks (ACTTION) group [29] has supported and recommended this definition in patients who have been prescribed medication for pain [25].

DSM-5 similarly specifies tolerance and withdrawal are not features of opioid use disorder in people taking opioids "solely under medical supervision" [2].. In an earlier paper examining DSM vs ICD definitions, DSM-\% did not agree well with DSM-IV, ICD-10 or ICD-11 (preliminary criteria) [11]. ICD11 displayed the best model fit [11]. For a comparison of the features across the different classification systems see Table 1.

Previous estimates of problematic opioid use in CNCP vary: 8-12\% for 'addiction' [36], DSM-5 lifetime pharmaceutical opioid use disorder ranged from $18.8 \%$ [11] to $41.3 \%$ [4] and lifetime ICD-11 opioid dependence 9.9\% [11]. However, assessment methods varied across studies, from examining clinical notes to administering a structured, well-validated questionnaire.

There has been no contrast of ICD and DSM definitions and the pain medicine concept of 'Addiction' in a sample of patients prescribed opioids for CNCP. This paper uses data from a large, national, community cohort of people prescribed opioids for CNCP, to examine:

1. The prevalence of people meeting criteria for the different definitions of opioid dependence and use disorder (DSM and ICD), and 'Addiction'

2. The degree of concordance between 'Addiction', DSM-IV, ICD-10 and ICD-11 'pharmaceutical opioid dependence', and the DSM-5 'opioid use disorder';

3. The socio-demographic and clinical characteristics of persons meeting the different sets of criteria for 'Addiction', DSM-5 and ICD-11; and

4. A comparison between those who meet criteria for 'Addiction' and those that do not meet criteria for any problematic use (i.e. DSM-IV, ICD-10, ICD-11 dependence and DSM-5 use disorder) and those who meet criteria for 'Addiction' only with those who meet criteria ICD11 dependence or criteria for DSM-5 pharmaceutical opioid use disorder.

\section{Method}




\section{Study design and setting}

The Pain and Opioid IN Treatment (POINT) study was designed to document patterns of pharmaceutical opioid use, and risk of adverse events and outcomes, in a prospective cohort of patients who were prescribed opioids for chronic non-cancer pain. The methodology of this cohort has been described in detail elsewhere [6]. The study was approved by the Human Research Ethics Committee of UNSW Australia (HREC reference: \# HC12149). The current study is based on data collected at the two-year time point. Included in the current paper is a sample of 1,134 participants who had completed the two-year interview and had been prescribed opioids in the preceding 12 months.

\section{Eligibility criteria}

At study enrolment POINT participants were: 18 years or older; taking opioids for CNCP for more than 6 weeks; competent in English; mentally and physically able to undertake telephone and selfcompletion interviews; without serious cognitive impairments; living with chronic non-cancer pain; prescribed an opioid such as morphine, oxycodone or fentanyl (Schedule 8 in the Australian classification of 'drugs of dependence' and subject to additional regulatory controls regarding manufacture, supply, distribution, possession and use [32]. A history of injecting drug use was not an exclusion criterion, but those currently prescribed pharmaceutical opioids for opioid substitution therapy (OST) for heroin dependence or taking opioids for cancer pain were not eligible. Of the 2,091 participants assessed for eligibility, 90\% ( $n=1873)$ were eligible and 1514 completed the baseline interview ( $n=201$ refused after being deemed eligible and 100 were unable to be contacted). We had a completion rate of $82 \%(n=1,245)$ at the two-year time point; 113 participants have withdrawn over the two-years, 45 have died and 111 participants had discontinued pharmaceutical opioid use 12 months or more prior to interview.

Phone interviews were conducted by trained interviewers who had received training in the computer assisted personnel interviewing survey schedule. Interviewers had a minimum 3-year health or psychology degree, were trained in how to respond to reports of suicidal thoughts or suicidal plans, and were provided with glossaries of chronic pain medications and conditions.

The measures, tools, and domains collected were based on recommendations made under the auspices of the Initiative on Methods, Measurement, and Pain Assessment in Clinical Trials 
(IMMPACT) [13; 33]. The six core domains identified as being important in measuring core outcomes included pain, physical functioning, emotional functioning, participant ratings of improvement and satisfaction with treatments, symptoms and adverse events and participant disposition. Full details of the measures used in the study have been reported elsewhere [6].

\section{Assessment of DSM and ICD dependence and pharmaceutical opioid use disorders and 'Addiction'}

Pharmaceutical opioid use disorders were assessed using the Composite International Diagnostic Interview 3.0 (CIDI) [15]. The CIDI has been used widely in epidemiological studies in many countries $[12 ; 16 ; 26]$, and has been shown to have excellent inter-rater reliability [15], test-retest reliability [15], and concordance with clinician diagnoses [14]. 'Addiction', and ICD and DSM diagnoses were determined from the CIDI responses. 'Addiction' and the criteria and the numbers of patients included in the various definitions are reported in Table 1 (see Appendix A for operationalisation of criteria, available online as Supplemental Digital Content at http://links.Iww.com/PAIN/A251).

For participants who used medications as prescribed $(n=928)$, the criteria of tolerance and withdrawal were not included for assessing fit with DSM-5 diagnoses. However, in those who endorsed at least one aberrant behaviour, as collected in the Opioid Related Behaviours in Treatment (ORBIT) scale, tolerance and withdrawal were included in assessing fit with DSM-5 opioid use disorder $(n=206)$. Aberrant behaviours included were injection, tampering, doctor shopping, or diversion of opioids.

\section{Pain and physical health measures}

Current pain severity and pain interference were measured by the Brief Pain Inventory [8] as a continuous score from zero to 10. Using the Pain Self-Efficacy Questionnaire [1], a cut-off of 30 was used, as scores $<30$ have been shown to indicate less sustainable gains, and to predict a lower rate of return to work and/or maintenance of treatment gains [9]. Participants were asked for how long they had been in pain and from how many prescribers they had received their medication. Health service utilisation was defined as ever having surgery for pain, having been in a pain management course, or having seen a psychiatrist or psychologist.

The Short Form 12 (SF12) is a measure of general health functioning. It provides a physical and mental health component core and there are population norms, with a mean score of 50 and a SD of 
10. In the current study, we only used the physical dimension. A cut-off of two standard deviations below the population mean was used to indicate severity in the current study.

\section{Medications and problematic opioid use measures}

Daily oral morphine equivalent (OME) doses for the pharmaceutical opioids taken by the cohort were estimated following review and synthesis of a range of clinical guidelines [22]. Current average daily dose (OME mgs/day) was calculated using opioid consumption from a one-week medication diary completed as part of the 2-year interview. OME were calculated for the 1,035 participants that reported past week opioid medication consumption.

The Prescribed Opioids Difficulty Scale (PODS) was used to measure participants' current problems and concerns about using prescribed opioids [31]. We used a continuous score on both the problems and the concerns domain on the PODS. The problems domain includes items such as "caused me to have difficulty remembering", "caused me to lose interest", and "caused me to feel depressed". The concern domain includes items such as preoccupation with medication, needing a higher dose, wanting to cut down, feeling dependent on medication and medication causing problems in work and social settings alert [31].

The ORBIT is a 10-item measure of aberrant or non-adherent behaviours such as doctor shopping, diversion and other examples of unsanctioned use of medications. Each item is scored between zero to four to give a continuous score from 0-40 [19].

\section{Mental health and substance use}

Depression and generalized anxiety disorder were measured by the PHQ-9 and GAD-7 modules of the Patient Health Questionnaire [17; 18]. Previously validated cut-offs were used as follows: moderate to severe depression was defined as a score of $\geq 10$ on the PHQ-9 [17] and moderate to severe anxiety was defined as a score of $\geq 10$ on the GAD-7 [30].

A score of $\geq 3$ on the Primary Care PTSD screen (PC-PTSD) was used to indicate PTSD [23]. Participants were asked about lifetime and past 12 month alcohol and illicit drug use. Lifetime drug 
and alcohol use disorders (using ICD-10 dependence criteria) were assessed via the alcohol and drug use module of the Composite International Diagnostic Interview (CIDI) [37].

The following questions on childhood maltreatment were asked, based on questions by Sansone [24] : "Before the age of 16, did you experience sexual abuse, physical abuse, emotional abuse, physical neglect, emotional and/or did you witness any violence." . In the current study only data from the sexual, physical and emotional abuse questions were used and were combined into one dichotomous variable of 'any childhood abuse'.

\section{Data analysis}

Analyses used STATA, version 12.0 (Stata Corporation, College Station, TX, USA). We reported the frequency of participants meeting each criterion for pharmaceutical opioid use disorder and dependence according to the five classification systems. We also examined the concordance between numbers of participants meeting criteria for each definition of disorder and concordance between each of the 'Addiction' criterion and the other diagnostic systems. Kappa, bias adjusted kappa (BAK), sensitivity, specificity and positive and negative predictive values are reported [20] to determine concordance between the 'Addiction' symptoms and the other classification systems. Kappa interpretation was based those recommended by Viera and Garrett [35], these were; less than 0 less than chance agreement, 0.01-0.20 slight agreement, 0.21-0.40 fair agreement, 0.61-0.80 substantial agreement, 0.81-0.99 almost perfect agreement.

Proportions, means and standard deviations were reported. Where data were non-normally distributed we reported median and inter-quartile range (IQR). Binary logistic regressions were used to examine characteristics associated with concept of addiction compared to those that did not meet criteria for any problematic use, according to traditional systems, and those that met criteria for 'Addiction' only, compared with ICD-11 dependence and DSM-5 use disorder. To understand the characteristics of the participants who met criteria for 'Addiction' ( $n=271)$ we compared them with those that did not meet criteria for any of the of the classification systems, including, DSM-IV, ICD-10, ICD-11 dependence and DSM-5 used disorder $(n=823)$. To understand characteristics of participants captured under the concept of 'Addiction', that were not included in the traditional classification systems of ICD-11 dependence and DSM-5 use disorder, we compared an 'Addiction' only group with 
all who met criteria for DSM-5 ( $n=104$ vs 202 respectively) and all who met criteria for ICD-11 ( $n=69$ vs 213 respectively). Odds ratios and $95 \%$ Confidence Intervals are reported.

\section{Results}

Of the participants, $57 \%$ were female (95\% Cl 54-60), the median age was 60 (IQR 51-69), 43\% were unemployed $(95 \% \mathrm{Cl} 40.0-46.2)$ and they had been prescribed opioids continuously for a median of 7 years (IQR 4-13). The most common pain conditions reported in the past 12 months were back and neck problems $(85 \%, 95 \% \mathrm{Cl} 82.8-87.5)$, followed by arthritis/rheumatism $(76 \%, 95 \% \mathrm{Cl} 69.5-75.4)$ and frequent headaches or migraines $(33.1,95 \% \mathrm{Cl} 30.0-36.3)$. The vast majority $(87 \%, 95 \% \mathrm{Cl} 84.8-89.1)$ reported the presence of more than one pain condition in the preceding 12 months.

Twenty-five percent of the sample met criteria for physical dependence (as defined by withdrawal), and $13 \%$ met criteria for tolerance. Prevalence of problematic use differed depending on the classification system used (Table 1). The prevalence of Dependence as defined by DSM-IV or ICD-10 was similar $(8.4 \%, 95 \% \mathrm{Cl} 7.0-10.2$ and $9.4 \%, 95 \% \mathrm{Cl} 7.8-11.2$, respectively). Nineteen percent met ICD-11 criteria for Dependence, $18 \%$ met criteria for DSM-5 use disorder, and $24 \%$ met criteria for 'Addiction'. The relationship between ICD-11 and DSM-5 and 'Addiction' are presented in Figure 1.

\section{Table 1 and figure 1 here}

Measures of concordance between the diagnostic systems are presented in Table 2. There was moderate concordance between 'Addiction' and DSM-IV, ICD-10 dependence (kappa 0.46 and 0.48, respectively). There was substantial concordance between 'Addiction' and DSM-5 use disorder and ICD-11 dependence (kappa 0.63 and 0.79 , respectively). None of the classification systems was shown to have excellent concordance with the definition of 'Addiction'

\section{Table 2 here}

Measures of concordance between the individual criteria for 'Addiction' and corresponding criteria within each of the classification systems are presented in Table 3. Impaired control was the most decisive criterion for 'Addiction' (PPV 1.00, NPV 0.95). The remaining three criteria showed lower 
specificity values and much lower bias-adjusted kappas (see Table 3). Amongst the other classification systems, given that each comprise polythetic symptom sets, there was only fair-tomoderate concordance between 'Addiction' criteria and DSM-IV and ICD-10 dependence, and DSM-5 use disorder. There was substantial concordance with impaired control and ICD-11 dependence (kappa 0.72 ), but only slight-to-fair concordance amongst the remaining three criteria.

\section{Table 3 here}

Clinical and socio-demographic characteristics of the cohort who meet criteria for 'addiction', DSM-5 'use disorder' and ICD-11 'dependence' are presented in Table 4. Only data for 'Addiction', use disorder according to DSM-5 and dependence according to ICD-11 are presented. See Appendix B (available online as Supplemental Digital Content at http://links.Iww.com/PAIN/A251) for results on dependence according to DSM-IV and ICD-10. Participants who met criteria for 'Addiction', compared with those who met no diagnostic criteria for problematic use (DSM-IV, ICD-10, ICD-11 dependence and DSM-5 use disorder), were more likely to be male, younger, less likely to be in a married or defacto relationship, more likely to report more mental health problems, substance use histories,,,, greater patient-centred problems, more aberrant or non-adherent medication behaviours associated with their opioid use, and a higher OME (Table 4, column E).

No differences were identified between those who did not meet criteria for any dependence/use disorder ( $n=1043$ ) and those who met criteria for 'Addiction' only (i.e. did not meet criteria for any other classification of 'dependence' or 'opioid use disorder' $n=51$, comparison not shown in Table 4).

Compared with those meeting criteria for DSM-5 'opioid use disorder' ( $n=202)$, participants who met criteria for 'addiction' only (i.e. those who met criteria for 'Addiction' and not DSM-5, n=202) (Table 4, column F), referred to as the 'Addiction' only group, were significantly less likely to report having engaged in non-adherent or aberrant behaviours in the preceding three months, less likely to report problems or concerns with their opioid use, less likely to suffer mental health problems or to have seen a mental health professional, or to have ever been in substance use treatment, and reported fewer side effects, pain interference, poor pain self-efficacy scores. Further, the 'Addiction' only group was also older and less likely to be unemployed, when compared with those who met criteria for opioid use disorder according to DSM-5. 
Compared with those who met criteria for ICD-11 'opioid dependence' ( $n=213$, Table 4, column G), the 'Addiction' only group (i.e. those who met criteria for 'Addiction' only and not ICD-11 dependence, $n=69$ ) was significantly less likely to report aberrant behaviours, problems and concerns with their opioid use, but had more mental health problems and were more likely to have ever seen a health professional. They were also more likely to be older, in a married/defacto relationship and less likely to be unemployed or have completed year 10 of school education.

\section{Table 4 here}

\section{Discussion}

There have been difficulties in determining rates of addiction/dependence in people prescribed opioids for pain, arising out of a lack of consistency in terminology and measures used [36]. This is the first study comparing pain medicine criteria for 'Addiction' with standard diagnostic criteria for opioid use disorder in people prescribed opioids for CNCP. In this cohort, over the previous 12 months, $23.9 \%$ met criteria for 'Addiction', $18.8 \%$ for ICD-11 dependence, $17.8 \%$ for DSM-5 pharmaceutical opioid use disorder, and similar proportions met criteria for DSM-IV and ICD-10 pharmaceutical opioid dependence ( $9.4 \%$ and $8.4 \%$, respectively). There was moderate concordance between classifications for 'Addiction' and DSM-IV, 'Addiction' and ICD-10 dependence and substantial concordance between 'Addiction' and DSM-5 use disorder and 'Addiction' and ICD-11 dependence. The current study highlights the importance of empirically testing the competing definitions of opioid dependence and addiction.

Those who met 'Addiction' criteria were significantly more likely than those who did not meet criteria for a disorder in any of the classification systems to have greater pain severity, more interference from their pain and to have engaged in non-adherent behaviours. They also reported more problems and concerns with their opioid medication use, had more mental health issues and a greater substance use history.

At face-value therefore, the pain medicine concept of 'Addiction' seems to have high sensitivity in identifying people with a range of behaviours or traits often associated with opioid dependence (i.e., substance use histories and non-adherent behaviours). However, comparisons of those who met 
criteria for 'Addiction' only with those who met criteria for ICD-11 and DSM-5 showed that the 'Addiction only' group were less likely to engage in aberrant behaviours or to have problems with their use and had lower rates of psychological distress, and substance use histories. This suggests that the addiction definition is capturing a broader group, including some patients who may be showing fewer problem behaviours, than those captured by existing diagnostic criteria (i.e. ICD11, DSM-5). Finally, there were no differences between the people who were identified only by the 'Addiction' concept (and not by any of the other classification systems) and people who did not meet criteria for any of the classification systems.

There are potential clinical implications of the lower threshold for an 'Addiction' diagnosis compared with other dependence classification systems. It may be argued that the broader 'addiction' diagnosis may help target clinical strategies such as closer monitoring, safer prescribing and dispensing practices and a greater emphasis upon non-opioid interventions. However, a definition that is too broad may mean that some people who are not experiencing (and may never develop) problematic opioid use may be stigmatised with a label of 'Addiction', and may be subjected to unnecessary or even potentially counter-therapeutic interventions and/or changes to their treatment plans. It is important in CNCP treatment to balance the need for effective pain relief with strategies that aim to reduce problematic opioid use.

Another controversial issue in the use of traditional classification systems in pain medicine is whether or not tolerance and withdrawal criteria should be included. In the current sample, $25.6 \%$ met criteria for physical dependence (i.e. withdrawal), and 14.2\% met criteria for tolerance. It has been argued that the term dependence, according the ICD and DSM classifications, is confusing because it includes both physical and psychological dependence [28]. Current definitions of 'Addiction' among people prescribed long-term opioids for pain have not been empirically derived, although there has been a strong clinical consensus supporting the exclusion of the features of 'tolerance' and 'withdrawal' in identifying problematic use. Physical dependence is an expected response to prolonged exposure to opioids, and where a patient is prescribed opioids for a period of time, they may experience withdrawal symptoms when they cease. Psychological dependence, as used in the DSM and ICD [28] encompasses a broader behavioural syndrome, see (Table 1). The DSM-5 'opioid use disorder' classification attempted to address this issue by conditionally excluding tolerance and physical dependence criteria in patients who used opioid medications 'solely as prescribed', and these criteria were used in the current study. 
The development of the 'addiction' classification in pain medicine arose out of a concern that too many individuals may be inappropriately diagnosed as 'dependent' according to the then DSM-IV or ICD-10, given theinclusion of withdrawal and tolerance in those diagnostic systems (Ballantyne et al). It is of interest that while our study found 'substantial' concordance between 'Addiction' and DSM-5 use disorder and between 'addiction' and ICD-11 dependence, concordance was far greater for the latter. In a previous paper [11], we found that DSM-5 had low concordance compared with other classifications (i.e. ICD-11, ICD-10, and DSM-IV). Criticisms of the DSM-5 suggest that the broader use of the term opioid use disorder, which encompasses both dependence and abuse criteria, does not equate to 'dependence'. It is unclear which particular patient group the DSM-5 now describes, but it appears to be different from those identified by ICD-10, by ICD-11, by DSM-IV dependence and by the pain medicine concept of 'Addiction'.

Of importance, the ICD and DSM classification systems were not designed specifically to address pharmaceutical drug use in patients using medications under medical supervision. The salience of concepts such as 'taking a substance in larger amounts or for longer than you intend to', 'wanting to cut down', or 'persistent use despite harms' are yet to be well understood from the perspective of the pain patient. This is especially challenging where medications have positives as well as negatives in the context of medical treatment, meaning motivations to continue or to cease medication may be unrelated to the construct of dependence, and is an important area for further work. Many such behaviours or cognitions (desire to cut down, prolonged use, use despite harms such as side effects) occur in patients taking medications for chronic conditions that are not CNS active, and hence may not necessarily signify dependence or addiction. This highlights that the current classification systems for dependence have been historically developed for substances such as alcohol and illicit drugs. This paper examines the best definitions available, but over time diagnostic criteria may be refined to better capture problems with medications used in a prescribed context.

\section{Strengths and limitations-}

This study used a large, national community sample of people prescribed opioids for CNCP to compare the performance of different diagnostic criteria. However, there is the potential that we did not succeed in recruiting a representative sample of people prescribed opioids for chronic pain. To investigate this possibility, additional data were collected from a random sample of pharmacies $(n=71)$ on the characteristics of all their opioid customers seen during the six week recruitment 
window. This revealed reassuring similarities with our sample. Among the total number of customers recorded as purchasing opioids in these pharmacies, $52 \%$ were female (vs $55 \%$ in the POINT cohort); and $7 \%$ were $18-34$ years, 55\% 35-64 years and 38\% 65+ years (vs. 5\%, 62\% and 33\% respectively, in the POINT cohort). Two thirds (63\%) were prescribed oxycodone (vs. 62\% in the POINT cohort), $16.5 \%$ prescribed morphine (vs. $15 \%$ in the POINT cohort), and $24 \%$ prescribed buprenorphine patches (vs. 21\% in the POINT cohort).

A further strength herein was that we measured medication nonadherence, unlike other studies that have examined the DSM-5 in people prescribed opioids for CNCP [4]. We were therefore able to determine which patients were using 'solely as prescribed' and so could apply the conditional exclusion of tolerance and withdrawal appropriately.

A limitation is the potential bias by reliance on self-report data. For instance, information on chronic medical illnesses and mental health problems were not verified through patient records, but the rates of pain conditions and findings were similar to those in previous research [5; 27]. Yet, all participants were informed that their responses would be de-identified and confidential, an assurance found to enhance the validity of self-reported substance use [10]. It is important to note that the current study was cross-sectional and future prospective studies, based on community samples, are necessary to determine which definitions of 'Addiction'/dependence are the most useful in identifying patients who encounter problems with their pharmaceutical opioid use. Finally, the definitions examined in this paper are based on information collected in an interview, rather than a diagnosis by a clinician; however, the CIDI has been found to be a reliable and valid method of diagnosing alcohol and substance use disorders [34] 


\section{Conclusion}

Although our study provides some empirical support for what has previously been based on clinical consensus, the 'addiction' concept used in pain medicine is broad and encompasses patients that may not be at high-risk of problematic opioid use. Even after applying conditional exclusion of tolerance and withdrawal, the DSM-5 pharmaceutical use disorder classification appears to capture a different patient group from those of other diagnostic systems. Patients identified by ICD-11 opioid dependence criteria were nearly all encompassed within the concept of 'addiction'. ICD-11 opioid dependence criteria seem to be the most promising in identifying those patients with CNCP who are experiencing significant problems in use, to inform their ongoing treatment planning.

\section{Acknowledgments}

Thanks to Jessica Belcher, Sarah Freckleton, Anika Martin, Bianca Hoban, Teleri Moore Ranira Moodley, Kimberley Smith and Rachel Urquhart-Secord, NDARC, for their contribution to data collection. We also thank Cerissa Papanastasiou, Burnet Institute, for her contribution to some of the POINT data collection in Melbourne Thanks to the Pharmacy Guild of Australia the NSW Pharmacy Guild and Pain Australia for their support of this study and assistance with dissemination. Thanks also to the POINT advisory committee for their advice on the design and conduct of the study.

This study received funding from the Australian National Health and Medical Research Council (NHMRC, \#1022522). LD, BL, SN, WH and RPM are supported by NHMRC research fellowships (\#1041472, \#1073858, \#1013803, \#569738 and \#1045318). The National Drug and Alcohol Research Centre at the University of NSW is supported by funding from the Australian Government under the Substance Misuse Prevention and Service Improvements Grant Fund. Cerissa Papanastasiou was supported by funding provided by the Victorian Drug Law Enforcement Fund.

\section{Conflict of interest}

$\mathrm{SN}, \mathrm{NL}, \mathrm{RB}, \mathrm{GC}, \mathrm{BL}, \mathrm{LD}$ have all been investigators on untied investigator-driven educational grants funded by Reckitt Benckiser for post-marketing surveillance studies of buprenorphine-naloxone tablets and film, development of an opioid-related behaviour scale, and/or a study examining the uptake of opioid substitution therapy among chronic non-cancer pain patients. NL, RB, BL and LD 
have received an untied educational grant from Mundipharma for post-marketing surveillance studies of Reformulated OxyContin ${ }^{\circledR}$. MC has received payments from Mundipharma Pty Limited for preparation and presentation of educational material

\section{References}

[1] Anderson KO, Dowds BN, Pelletz RE, Edwards WT, Peeters-Asdourian C. Development and initial validation of a scale to measure self-efficacy beliefs in patients with chronic pain. Pain 1995;63(1):77-83.

[2] Association AP. Diagnostic and Statistical Manual of Mental Disorders (DSM-5 ${ }^{\circledR}$ ): American Psychiatric Pub, 2013.

[3] Ballantyne JC. Assessing the prevalence of opioid misuse, abuse, and addiction in chronic pain. Pain 2015;156(4):567-568.

[4] Boscarino JA, Hoffman SN, Han JJ. Opioid-use disorder among patients on long-term opioid therapy: Impact of final DSM-5 diagnostic criteria on prevalence and correlates. Substance abuse and rehabilitation 2015;6:83.

[5] Braden J, Sullivan M. Suicidal ideation, plans and attempts among individuals with chronic pain conditions: Data from the National Co-morbidity Survey Replication. The Journal of Pain 2008;9(4, Supplement 2):70.

[6] Campbell G, Mattick R, Bruno R, Larance B, Nielsen S, Cohen M, Lintzeris N, Shand F, Hall WD, Hoban B, Kehler C, Farrell M, Degenhardt L. Cohort protocol paper: the Pain and Opioids In Treatment (POINT) study. BMC pharmacology \& toxicology 2014;15(1):17.

[7] Chou R, Turner JA, Devine EB, Hansen RN, Sullivan SD, Blazina I, Dana T, Bougatsos C, Deyo RA. The Effectiveness and Risks of Long-Term Opioid Therapy for Chronic Pain: A Systematic Review for a National Institutes of Health Pathways to Prevention WorkshopEffectiveness and Risks of Long-Term Opioid Therapy for Chronic Pain. Annals of Internal Medicine 2015;162(4):276-286.

[8] Cleeland C. Assessment of Pain in Cancer: Measurement Issues, in Anonymous. Proceedings of the Second International Congress on Cancer Pain 1990:47 - 56.

[9] Coughlan G, Ridout K, Williams AdC, Richardson P. Attrition from a pain management programme. British journal of clinical psychology 1995;34(3):471-479.

[10] Darke S. Self-report among injecting drug users: a review. . Drug and Alcohol Dependence 1998;51(3):10.

[11] Degenhardt L, Bruno R, Lintzeris N, Hall W, Nielsen S, Larance B, Cohen M, Campbell G. Agreement between definitions of pharmaceutical opioid use disorders and dependence in people taking opioids for non-cancer chronic pain (POINT): a cohort study. Lancet Psychiatry 2015; (in press).

[12] Demyttenaere K, Bruffaerts R, Lee S, Posada-Villa J, Kovess V, Angermeyer MC, Levinson D, de Girolamo G, Nakane H, Mneimneh Z. Mental disorders among persons with chronic back or neck pain: results from the World Mental Health Surveys. Pain 2007;129(3):332-342.

[13] Dworkin RH, Turk DC, Farrar JT, Haythornthwaite JA, Jensen MP, Katz NP, Kerns RD, Stucki G, Allen RR, Bellamy N, Carr DB, Chandler J, Cowan P, Dionne R, Galer BS, Hertz S, Jadad AR, Kramer LD, Manning DC, Martin S, McCormick CG, McDermott MP, McGrath P, Quessy S, Rappaport BA, Robbins W, Robinson JP, Rothman M, Royal MA, Simon L, Stauffer JW, Stein W, Tollett J, Wernicke J, Witter J. Core outcome measures for chronic pain clinical trials: IMMPACT recommendations. Pain 2005;113(1-2):9-19.

[14] Haro JM, Arbabzadeh-Bouchez S, Brugha TS, de Girolamo G, Guyer ME, Jin R, Lepine JP, Mazzi F, 
Reneses B, Vilagut G, Sampson NA, Kessler RC. Concordance of the Composite International Diagnostic Interview Version 3.0 (CIDI 3.0) with standardized clinical assessments in the WHO World Mental Health surveys. Int J Methods Psychiatr Res 2006;15(4):167-180.

[15] Kessler RC, Üstün TB. The World Mental Health (WMH) Survey Initiative version of the World Health Organization (WHO) Composite International Diagnostic Interview (CIDI). International Journal of Methods in Psychiatric Research 2004;13(2):93-121.

[16] Kessler RC, Üstün TB. The WHO World Mental Health Surveys: global perspectives on the epidemiology of mental disorders: Cambridge University Press New York, 2008.

[17] Kroenke K, Spitzer R, Williams JBW. The PHQ-9: Validity of a Brief Depression Severity Measure. Journal of General Internal Medicine 2001;16(9):606-613.

[18] Kroenke K, Spitzer RL, Williams JBW, Lowe B. The Patient Health Questionnaire Somatic, Anxiety, and Depressive Symptom Scales: a systematic review. General Hospital Psychiatry 2010;32(4):345-359.

[19] Larance B, Bruno R, Lintzeris N, Black E, Degenhardt L, Brown A, Nielsen S, Dunlop A, Holland R, Cohen M, Mattick RP. Development of the Opioid Related Behaviours In Treatment (ORBIT) scale. Drug and Alcohol Dependence Accepted November, 2015.

[20] Mackinnon A. A spreadsheet for the calculation of comprehensive statistics for the assessment of diagnostic tests and inter-rater agreement. Computers in biology and medicine 2000;30(3):127-134.

[21] Martell BA, O'Connor PG, Kerns RD, Becker WC, Morales KH, Kosten TR, Fiellin DA. Systematic review: opioid treatment for chronic back pain: prevalence, efficacy, and association with addiction. Annals of Internal Medicine 2007;146(2):116-127.

[22] Nielsen S, Degenhardt L, Hoban B, Gisev N. Comparing opioids: A guide to estimating oral morphine equivalents (OME) in research. NDARC Technical Report No. 329: National Drug and Alcohol Research Centre, UNSW Australia, 2014.

[23] Prins A, Ouimette P, Kimerling R, Camerond RP, Hugelshofer DS, Shaw-Hegwer J, Thrailkill A, Gusman FD, Sheikh JI. The primary care PTSD screen (PC-PTSD): development and operating characteristics. Primary Care Psychiatry 2004;9(1):9-14.

[24] Sansone RA, Whitecar P, Wiederman MW. The Prevalence of Childhood Trauma Among Those Seeking Buprenorphine Treatment. Journal of Addictive Diseases 2009;28(1):64-67.

[25] Savage S, Covington E, Heit H, Hunt J, Joranson D, Schnoll S. Definitions related to the use of opioids for the treatment of pain: A consensus document from the American Academy of Pain Medicine, the American Pain Society, and the American Society of Addiction Medicine. American Pain Society Advocacy and Policy 2001.

[26] Seedat S, Scott KM, Angermeyer MC, Berglund P, Bromet EJ, Brugha TS, Demyttenaere K, De Girolamo G, Haro JM, Jin R. Cross-national associations between gender and mental disorders in the World Health Organization World Mental Health Surveys. Archives of general psychiatry 2009;66(7):785-795.

[27] Smith MT, Edwards RR, Robinson RC, Dworkin RH. Suicidal ideation, plans, and attempts in chronic pain patients: factors associated with increased risk. Pain 2004;111(1-2):201-208.

[28] Smith SM, Dart RC, Katz NP, Paillard F, Adams EH, Comer SD, Degroot A, Edwards RR, Haddox JD, Jaffe JH, Jones CM, Kleber HD, Kopecky EA, Markman JD, Montoya ID, O'Brien C, Roland CL, Stanton M, Strain EC, Vorsanger G, Wasan AD, Weiss RD, Turk DC, Dworkin RH. Classification and definition of misuse, abuse, and related events in clinical trials: ACTTION systematic review and recommendations. Pain 2013;154(11):2287-2296.

[29] Smith SM, Paillard F, McKeown A, Burke LB, Edwards RR, Katz NP, Papadopoulos EJ, Rappaport BA, Slagle A, Strain EC, Wasan AD, Turk DC, Dworkin RH. Instruments to Identify Prescription Medication Misuse, Abuse, and Related Events in Clinical Trials: An ACTTION Systematic Review. The Journal of Pain 2015;16(5):389-411.

[30] Spitzer RL, Kroenke K, Williams JBW, Lowe B. A brief measure for assessing generalized anxiety disorder: the GAD-7. Archives of Internal Medicine 2006;166(10):1092-1097. 
[31] Sullivan M, Von Korff M, Banta-Green C, Merrill J, Saunders K. Problems and concerns of patients receiving chronic opioid therapy for chronic non-cancer pain. (19 refs.): University of Washington, School of Medicine, Department of Psychiatry \& Behavioral Science, Box 356560, Seattle, WA 98195. [E-mail: sullimar@u.washington.edu], 2010.

[32] Therapeutic Goods Administration. Standard for the Uniform Scheduling of Medicines and Poisons (SUSMP). In: Australian Government Department of Health and Ageing editor. http://wwwtgagovau/industry/scheduling-poisons-standardhtm Accessed on 05/09/2013, 2013.

[33] Turk DC, Dworkin RH, Allen RR, Bellamy N, Brandenburg N, Carr DB, Cleeland C, Dionne R, Farrar JT, Galer BS, Hewitt DJ, Jadad AR, Katz NP, Kramer LD, Manning DC, McCormick CG, McDermott MP, McGrath P, Quessy S, Rappaport BA, Robinson JP, Royal MA, Simon L, Stauffer JW, Stein W, Tollett J, Witter J. Core outcome domains for chronic pain clinical trials: IMMPACT recommendations. Pain 2003;106(3):337-345.

[34] Üstün B, Compton W, Mager D, Babor T, Baiyewu O, Chatterji S, Cottler L, Göğüş A, Mavreas V, Peters L, Pull C, Saunders J, Smeets R, Stipec MR, Vrasti R, Hasin D, Room R, Van den Brink W, Regier D, Blaine J, Grant BF, Sartorius N. WHO Study on the reliability and validity of the alcohol and drug use disorder instruments: overview of methods and results. Drug and Alcohol Dependence 1997;47(3):161-169.

[35] Viera AJ, Garrett JM. Understanding interobserver agreement: the kappa statistic. Fam Med 2005;37(5):360-363.

[36] Vowles KE, McEntee ML, Julnes PS, Frohe T, Ney JP, van der Goes DN. Rates of opioid misuse, abuse, and addiction in chronic pain: a systematic review and data synthesis. Pain 2015;156(4):569-576.

[37] World Health Organization. Composite International Diagnostic Interview, Version 3.0. Geneva: World Health Organization, 2001.

Fig 1: Past 12 month diagnosis of addiction, ICD-11 and DSM-5

A total - Addiction ( $n=271,23.9 \%$ of the total sample)

B total - DSM-5 use disorder ( $n=202,17.8 \%$ of the total sample)

C total - ICD-11 ( $n=213,18.8 \%)$

A only $-(n=51)$

B only $-(n=29)$

C only - $(n=5)$

$A B-$ Addiction/DSM-5 ( $n=167)$

$A C-$ Addiction/ICD-11 ( $n=201)$

ABC - Addiction/DSM-5/ICD-11 ( $n=148)$ 
Table 1: Definitions and their operationalisation and prevalence in the POINT cohort

\begin{tabular}{|c|c|c|c|}
\hline Term & Definition & Operationalisation & $\begin{array}{ll}\text { Prevalence } \\
95 \% \mathrm{Cl})\end{array}$ \\
\hline Addiction & $\begin{array}{l}\text { It is characterized by behaviours that include one or more of the following: impaired control over drug use, compulsive } \\
\text { use, continued use despite harm, and craving. }\end{array}$ & $\begin{array}{l}\text { At least one of the following (from CIDI): } \\
\text { impaired control over drug use, compulsive use, } \\
\text { continued use despite harm, and craving }\end{array}$ & $23.9(21.5-26.5)$ \\
\hline $\begin{array}{l}\text { Physical } \\
\text { dependence }\end{array}$ & $\begin{array}{l}\text { A state of adaptation that is manifested by a drug class specific withdrawal syndrome that can be produced by abrupt } \\
\text { cessation, rapid dose reduction, decreasing blood level of the drug, and/or administration of an antagonist. }\end{array}$ & Withdrawal (CIDI) & $25.6(23.1-28.2)$ \\
\hline Tolerance & $\begin{array}{l}\text { A state of adaptation in which exposure to a drug induces changes that result in a diminution of one or more of the } \\
\text { drug's effects over time }\end{array}$ & Tolerance (CIDI) & $14.2(12.3-16.4)$ \\
\hline $\begin{array}{l}\text { DSM-IV } \\
\text { dependence }\end{array}$ & $\begin{array}{l}\text { 1. Tolerance, as defined by either of the following: } \\
\text { (a) need for markedly increased amounts of the drug to achieve intoxication or desired effect. } \\
\text { (b) markedly diminished effect with continued use of the same amount of the drug. } \\
\text { 2. Withdrawal, as manifested by either of the following: } \\
\text { (a) the characteristic withdrawal syndrome for the drug } \\
\text { (b) the same (or a closely related) substance is taken to relieve or avoid withdrawal symptoms. } \\
\text { 3. The drug is often taken in larger amounts or over a longer period than was intended. } \\
\text { 4. There is a persistent desire or unsuccessful efforts to cut down or control drug use } \\
\text { 5. A great deal of time is spent in activities necessary to obtain the drug (e.g., visiting multiple doctors or driving long } \\
\text { distances), to use the drug, or to recover from its effects } \\
6 \text { Important social, occupational, or recreational activities are given up or reduced because of drug use. } \\
\text { 7. The drug use is continued despite knowledge of having a persistent or recurrent physical or psychological problem }\end{array}$ & At least three in the same 12 month period & $8.5(7.0-10.2)$ \\
\hline $\begin{array}{l}\text { DSM-5 use } \\
\text { disorder }\end{array}$ & $\begin{array}{l}\text { 1. Taking the opioid in larger amounts and for longer than intended } \\
\text { 2. Wanting to cut down or quit but not being able to do it } \\
\text { 3. Spending a lot of time getting, using, or recovering from use of the substance } \\
\text { 4. Cravings and urges to use the substance } \\
\text { 5. Not managing to do what you should at work, home or school, because of substance use } \\
\text { 6. Continuing to use, even when it causes problems in relationships } \\
\text { 7. Giving up important social, occupational or recreational activities because of substance use } \\
\text { 8. Using substances again and again, even when it puts the you in danger } \\
\text { 9. Continuing to use, even when the you know you have a physical or psychological problem that could have been } \\
\text { caused or made worse by the substance } \\
\text { 10. Needing more of the substance to get the effect you want (tolerance) } \\
\text { 11. Development of withdrawal symptoms, which can be relieved by taking more of the substance. }\end{array}$ & $\begin{array}{l}\text { At least } 2 \text { of the } 11 \text { in the same } 12 \text { month period, } \\
\text { applying conditional exclusions to the features of } \\
\text { tolerance and withdrawal where relevant. } \\
\text { - For people using medications, as prescribed, } \\
\text { the tolerance and withdrawal criteria are } \\
\text { not included. } \\
\text { - For people in the POINT sample, who } \\
\text { endorsed non-adherent behaviours such as } \\
\text { injection, tampering, doctor shopping, or } \\
\text { diversion of opioids, tolerance and } \\
\text { withdrawal were included }\end{array}$ & $17.8(15.7-20.2)$ \\
\hline $\begin{array}{l}\text { ICD-10 } \\
\text { dependence }\end{array}$ & $\begin{array}{l}\text { 1. Strong desire or sense of compulsion to take the drug. } \\
\text { 2. Impaired capacity to control drug-taking behaviour in terms of its onset, termination, or levels of use, as evidenced by; } \\
\text { the drug being often taken in larger amounts or over a longer period than intended; or by a persistent desire or } \\
\text { unsuccessful efforts to reduce or control drug use. } \\
\text { 3. A physiological withdrawal state when drug use is reduced or ceased, as evidenced by the characteristic withdrawal } \\
\text { syndrome for the drug, or by use of the same (or closely related) substance with the intention of relieving or avoiding } \\
\text { withdrawal symptoms. } \\
\text { 4. Evidence of tolerance to the effects of the drug, such that there is a need for significantly increased amounts of the } \\
\text { drug to achieve intoxication or the desired effect, or a markedly diminished effect with continued use of the same } \\
\text { amount of the drug. } \\
\text { 5. Preoccupation with drug use, as manifested by alternative pleasures or interests being given up or reduced because of } \\
\text { drug use, or a great deal of time being spent in activities necessary to obtain, take, or recover from the effects of the } \\
\text { drug. } \\
\text { 6. Persistent drug use despite clear evidence of harmful consequences, as evidenced by continued use when the } \\
\text { individual is actually aware, or may be expected to be aware, of the nature and extent of the harm. } \\
\text { 7. The drug use is continued despite knowledge of having a persistent or recurrent physical or psychological problem } \\
\text { that is likely to have been caused or exacerbated by the drug }\end{array}$ & $\begin{array}{l}\text { Three or more symptoms in the same } 12 \text { month } \\
\text { period }\end{array}$ & $9.4(7.8-11.2)$ \\
\hline
\end{tabular}


The DSM-IV criteria for substance abuse and substance dependence have been combined into a single substance use disorder specific to each substance of abuse within a new "addictions and related disorders" category. Each substance use disorder is divided into mild, moderate, and severe subtypes. Whereas DSM-IV substance abuse diagnostic criteria required only 1 symptom, a DSM-5 diagnosis even for just mild substance use disorder now requires at least 2 . 
Table 2: Concordance between different measures of problematic use in the POINT cohort

\begin{tabular}{|c|c|c|c|c|c|c|c|c|c|c|}
\hline & \multicolumn{2}{|c|}{$\begin{array}{l}\text { 'Addiction' } \\
(n=271)\end{array}$} & \multicolumn{2}{|c|}{$\begin{array}{l}\text { DSM-IV dependence } \\
(n=96)\end{array}$} & \multicolumn{2}{|c|}{$\begin{array}{l}\text { DSM-5 use disorder } \\
(n=202)\end{array}$} & \multicolumn{2}{|c|}{$\begin{array}{c}\text { ICD-10 dependence } \\
(n=106)\end{array}$} & \multicolumn{2}{|c|}{$\begin{array}{l}\text { ICD-11 dependence } \\
(n=213)\end{array}$} \\
\hline & $\begin{array}{c}\text { No } \\
(n=861)\end{array}$ & $\begin{array}{c}\text { Yes } \\
(n=271)\end{array}$ & $\begin{array}{c}\text { No } \\
(n=1037)\end{array}$ & $\begin{array}{c}\text { Yes } \\
(n=96)\end{array}$ & $\begin{array}{c}\text { No } \\
(n=931)\end{array}$ & $\begin{array}{c}\text { Yes } \\
(n=202)\end{array}$ & $\begin{array}{c}\text { No } \\
(n=1026)\end{array}$ & $\begin{array}{c}\text { Yes } \\
(n=106)\end{array}$ & $\begin{array}{c}\text { No } \\
(n=921)\end{array}$ & $\begin{array}{c}\text { Yes } \\
(n=213)\end{array}$ \\
\hline 'Addiction' & & & \multicolumn{2}{|c|}{ Kappa 0.46} & \multicolumn{2}{|c|}{ Kappa 0.63} & \multicolumn{2}{|c|}{ Kappa 0.48} & \multicolumn{2}{|c|}{ Kappa 0.79} \\
\hline No & & & 83.1 & 0.00 & 88.8 & 17.3 & 83.7 & 1.9 & 92.5 & 5.2 \\
\hline Yes & & & 16.9 & 100 & 11.2 & 82.7 & 16.3 & 98.1 & 7.5 & 94.8 \\
\hline DSM-IV dependence & \multicolumn{2}{|c|}{ Kappa 0.46} & & & \multicolumn{2}{|c|}{ Kappa 0.55} & \multicolumn{2}{|c|}{ Kappa 0.88} & \multicolumn{2}{|c|}{ Kappa 0.57} \\
\hline No & 100 & 64.6 & & & 99.3 & 55.9 & 99.4 & 15.1 & 100 & 54.9 \\
\hline Yes & 0.0 & 35.4 & & & 0.7 & 44.1 & 0.6 & 84.9 & 0.0 & 45.1 \\
\hline DSM-5 use disorder & \multicolumn{2}{|c|}{ Kappa 0.63} & \multicolumn{2}{|c|}{ Kappa 0.55} & & & \multicolumn{2}{|c|}{ Карра 0.58} & \multicolumn{2}{|c|}{ Карра 0.69} \\
\hline No & 95.9 & 38.4 & 89.1 & 7.3 & & & 89.8 & 8.5 & 94.9 & 27.2 \\
\hline Yes & 4.1 & 61.6 & 10.9 & 92.7 & & & 10.2 & 91.5 & 5.1 & 72.8 \\
\hline ICD-10 dependence & \multicolumn{2}{|c|}{ Карра 0.48} & \multicolumn{2}{|c|}{ Карра 0.88} & \multicolumn{2}{|c|}{ Карра 0.58} & & & \multicolumn{2}{|c|}{ Kappa 0.62} \\
\hline No $\quad$ & 99.8 & 61.6 & 98.5 & 6.3 & 99.0 & 52.0 & & & 100 & 50.2 \\
\hline Yes & 0.2 & 38.4 & 1.5 & 93.8 & 1.0 & 48.0 & & & 0 & 49.8 \\
\hline ICD-11 dependence & \multicolumn{2}{|c|}{ Карра 0.79} & \multicolumn{2}{|c|}{ Kappa 0.57} & \multicolumn{2}{|c|}{ Kappa 0.69} & \multicolumn{2}{|c|}{ Kappa 0.62} & & \\
\hline No & 98.7 & 25.5 & 88.7 & 0.0 & 93.8 & 23.3 & 89.6 & 0.0 & & \\
\hline Yes & 1.3 & 74.5 & 11.3 & 100.0 & 6.2 & 76.7 & 10.4 & 100.0 & & \\
\hline
\end{tabular}


Table 3: Concordance between each 'Addiction' criteria and different measures of problematic use in the POINT cohort

\begin{tabular}{|c|c|c|c|c|c|c|}
\hline & & $\begin{array}{c}\text { Sensitivity } \\
\text { (\% true positive / } \\
\text { total positive) }\end{array}$ & $\begin{array}{c}\text { Specificity } \\
\text { (\% true } \\
\text { negative/total } \\
\text { negative) }\end{array}$ & $\begin{array}{c}\text { Positive predictive } \\
\text { value }\end{array}$ & $\begin{array}{l}\text { Negative predictive } \\
\text { value }\end{array}$ & $\begin{array}{c}\text { Bias adjusted } \\
\text { kappa }\end{array}$ \\
\hline \multirow[t]{5}{*}{ Impaired control } & Addiction & 81.9 & 100 & 1.00 & 0.95 & 0.87 \\
\hline & DSM-IV dependence & 84.4 & 86.4 & 0.36 & 0.98 & 0.43 \\
\hline & DSM-5 opioid use disorder & 67.3 & 90.8 & 0.61 & 0.93 & 0.56 \\
\hline & ICD-10 opioid dependence & 80.2 & 86.6 & 0.38 & 0.98 & 0.44 \\
\hline & ICD-11 & 78.9 & 94.1 & 0.76 & 0.95 & 0.72 \\
\hline \multirow[t]{5}{*}{ Compulsive use } & Addiction & 30.6 & 100 & 1.00 & 0.82 & 0.37 \\
\hline & DSM-IV dependence & 58.3 & 97.4 & 0.67 & 0.96 & 0.59 \\
\hline & DSM-5 opioid use disorder & 36.1 & 98.9 & 0.88 & 0.88 & 0.44 \\
\hline & ICD-10 opioid dependence & 54.7 & 97.6 & 0.70 & 0.95 & 0.58 \\
\hline & ICD-11 & 35.2 & 99.1 & 0.90 & 0.87 & 0.43 \\
\hline \multirow{5}{*}{$\begin{array}{c}\text { Continued use despite } \\
\text { harm }\end{array}$} & Addiction & 19.9 & 100 & 1.00 & 0.80 & 0.22 \\
\hline & DSM-IV dependence & 44.8 & 98.9 & 0.80 & 0.95 & 0.54 \\
\hline & DSM-5 opioid use disorder & 25.2 & 99.7 & 0.94 & 0.86 & 0.32 \\
\hline & ICD-10 opioid dependence & 40.6 & 98.9 & 0.80 & 0.94 & 0.50 \\
\hline & ICD-11 & 23.5 & 99.6 & 0.93 & 0.85 & 0.29 \\
\hline \multirow[t]{5}{*}{ Craving } & Addiction & 17.0 & 100 & 1.00 & 0.79 & 0.17 \\
\hline & DSM-IV dependence & 24.4 & 98.7 & 0.72 & 0.94 & 0.43 \\
\hline & DSM-5 opioid use disorder & 20.3 & 99.5 & 0.89 & 0.85 & 0.25 \\
\hline & ICD-10 opioid dependence & 36.8 & 99.3 & 0.85 & 0.94 & 0.48 \\
\hline & ICD-11 & 19.7 & 99.6 & 0.91 & 0.84 & 0.24 \\
\hline
\end{tabular}


Table 4: Opioid use and health service utilisation of the POINT cohort according to problematic use definitions ( $n=1134$ )

\begin{tabular}{|c|c|c|c|c|c|c|c|}
\hline & $\begin{array}{l}\text { A. Do not meet } \\
\text { criteria for any } \\
\text { problem use } \\
n=823\end{array}$ & $\begin{array}{l}\text { B. "Addiction" } \\
\mathrm{n}=271\end{array}$ & $\begin{array}{l}\text { C. DSM-5 opioid } \\
\text { use disorder } \\
n=202\end{array}$ & $\begin{array}{c}\text { D. ICD-11 } \\
\text { dependence } \\
n=213\end{array}$ & $\begin{array}{l}\text { E. A (ref) vs B } \\
\text { (271 vs } 823) \\
\text { OR }(95 \% \mathrm{Cl})\end{array}$ & $\begin{array}{l}\text { F. Addiction only vs } \\
\text { DSM-5 (C.) (ref) } \\
(104 \text { vs 202) } \\
\text { OR }(95 \% \mathrm{Cl})\end{array}$ & $\begin{array}{l}\text { G. Addiction only } \\
\text { VS ICD-11 (D.)(ref) } \\
\text { (69 vs 213) } \\
\text { OR }(95 \% \mathrm{Cl})\end{array}$ \\
\hline \multicolumn{8}{|l|}{ History of opioid use } \\
\hline Years of prescribed opioid use (MDN IQR) & $7(4-13)$ & $6(4-14)$ & $6(4-12)$ & $6(4-12)$ & $99.7(0.98-1.01)$ & $1.03(1.00-1.06)^{*}$ & $1.02(0.99-1.05)$ \\
\hline $\begin{array}{l}\text { Years since first symptom of problems related to prescribed } \\
\text { opioids (MDN IQR) }\end{array}$ & $5(3-11.5)$ & $4(3-8)$ & $5(3-8)$ & $4(3-7.5)$ & $0.97(0.94-1.00)^{*}$ & $1.02(0.97-1.07)$ & $1.03(0.97-1.09)$ \\
\hline Current OME (MDN, IQR) & $65.0(34.2-150.0)$ & $104.2(45.0-178.7)$ & $111(50-180)$ & $111(47.4-180)$ & $1.00(1.00-1.00)^{*}$ & $1.00(1.00-1.00)$ & $1.00(1.00-1.00)$ \\
\hline Past 3 month non-adherence score (ORBIT) (MDN, IQR) & $0(0-1)$ & $1(0-2)$ & $1(0-3)$ & $1(02)$ & $1.27(1.18-1.38)^{* * *}$ & $0.78(0.68-0.90)^{* *}$ & $0.86(0.74-1.00)^{*}$ \\
\hline Problems with prescribed opioids (PODS) score (MDN, IQR) & $3(0-8)$ & $9(2-19)$ & $14(5-21)$ & $11(4-21)$ & $1.09(1.07-1.10)^{* * *}$ & $0.91(0.89-0.94)^{* * *}$ & $0.92(0.90-0.96)^{* * *}$ \\
\hline Concerns with prescribed opioids (PODS) score (MDN, IQR) & $4(0-8)$ & $12(8-16)$ & $12(8-20)$ & $12(8-20)$ & $1.19(1.16-1.22)^{* * *}$ & $0.89(0.85-0.93)^{* * *}$ & $0.87(0.82-0.91)^{* * *}$ \\
\hline \% opioid side effects (PADT) & $75.3(72.3-78.2)$ & $81.9(76.8-86.1)$ & $86.6(81.2-90.7)$ & $83.6(77.9-88.0)$ & $1.48(1.05-2.10)^{*}$ & $0.44(0.24-0.80)^{* *}$ & $0.65(0.33-1.27)$ \\
\hline \multicolumn{8}{|l|}{ Service utilisation } \\
\hline \% more than one opioid prescriber+ & $14.6(12.3-17.2)$ & $19.9(15.6-25.1)$ & $19.3(14.4-25.4)$ & $20.2(15.3-26.2)$ & $1.46(1.02-2.08)^{*}$ & $0.87(0.47-1.62)$ & $0.78(0.36-1.55)$ \\
\hline \% ever mental health professional+ & $41.6(38.2-44.9)$ & $61.3(55.3-66.9)$ & $64.9(58.0-71.2)$ & $64.3(57.6-70.5)$ & $2.22(1.68-2.94)^{* * *}$ & $0.59(0.36-0.95)^{*}$ & $0.57(0.33-0.99)^{*}$ \\
\hline \multicolumn{8}{|l|}{ Clinical correlates } \\
\hline Median pain severity (SD) & $5.0(1.8)$ & $5.3(1.8)$ & $5.4(1.8)$ & $5.3(1.8)$ & $1.11(1.02-1.19)^{*}$ & $0.90(0.79-1.03)$ & $1.01(0.87-1.18)$ \\
\hline Median pain interference (SD) & $5.2(2.3)$ & $6.0(2.3)$ & $6.4(2.2)$ & $6.2(2.3)$ & $1.18(1.11-1.26)^{* * *}$ & $0.80(0.72-0.89)^{* * *}$ & $0.90(0.80-1.01)$ \\
\hline \% low pain self-efficacy (<30 PSEQ) & $37.5(34.2-40.8)$ & $49.8(43.9-55.8)$ & $57.9(50.9-64.6)$ & $52.6(45.8-59.3)$ & $1.66(1.26-2.18)^{* * *}$ & $0.29(0.18-0.48)^{* * *}$ & $0.65(0.38-1.13)$ \\
\hline$\%$ poor physical functioning (<30 SF-12)+ & $72.9(69.5-76.1)$ & $63.7(57.1-69.8)$ & $64.6(56.8-71.7)$ & $62.9(55.4-69.9)$ & $0.65(0.47-0.90)^{* *}$ & $1.00(0.58-1.70)$ & $1.15(0.62-2.12)$ \\
\hline \% Current generalised anxiety disorder & $11.6(9.6-14.0)$ & $28.0(23.0-33.7)$ & $38.6(32.1-45.6)$ & $32.9(26.8-39.5)$ & $2.97(2.12-4.18)^{* * *}$ & $0.23(0.12-0.43)^{* * *}$ & $0.31(0.14-0.65)^{* *}$ \\
\hline \% Current moderate to severe depression & $30.6(27.5-33.8)$ & $56.8(50.8-62.6)$ & $67.3(60.5-73.5)$ & $60.6(53.8-67.0)$ & $2.99(2.25-3.96)^{* * *}$ & $0.28(0.16-0.46)^{* * *}$ & $0.47(0.27-0.82)^{* *}$ \\
\hline$\%$ post-traumatic stress disorder + & $11.3(9.3-13.7)$ & $24.9(19.2-29.5)$ & $25.7(20.1-32.3)$ & $26.3(20.8-32.7)$ & $2.49(1.75-3.54)^{* * *}$ & $0.60(0.33-1.10)$ & $0.53(0.26-1.08)$ \\
\hline \% lifetime alcohol use disorder+ & $28.3(25.3-31.4)$ & $39.5(33.8-45.5)$ & $39.1(32.6-46.0)$ & $41.3(34.8-48.1)$ & $1.69(1.27-2.26)^{* * *}$ & $0.97(0.60-1.58)$ & $0.86(0.49-1.50)$ \\
\hline \% lifetime illicit drug use disorder**+ & $11.3(9.3-16.7)$ & $22.1(17.6-27.5)$ & $26.2(20.6-32.8)$ & $25.8(20.3-32.2)$ & $2.23(1.56-3.20)^{* * *}$ & $0.55(0.30-1.01)$ & $0.49(0.23-1.02)$ \\
\hline$\%$ family history of problematic use+ & $3.8(2.7-5.5)$ & $8.9(5.6-14.0)$ & $10.8(6.7-17.0)$ & $9.9(6.5-14.7)$ & $2.29(1.32-3.99)^{* *}$ & $0.46(0.15-1.42)$ & $0.27(0.06-1.20)$ \\
\hline \% ever treatment for SUD + & $7.8(6.1-9.8)$ & $19.2(14.9-24.4)$ & $24.8(19.2-31.2)$ & $22.1(17.0-28.2)$ & $2.9(1.9-4.2)^{* * *}$ & $0.29(0.14-0.61)^{* *}$ & $0.46(0.21-1.04)$ \\
\hline$\%$ childhood maltreatment+ & $48.6(45.2-52.0)$ & $61.3(55.3-66.9)$ & $62.9(55.9-69.3)$ & $65.7(59.0-71.8)$ & $1.67(1.26-2.21)^{* * *}$ & $0.81(0.50-1.30)$ & $0.60(0.35-1.05)$ \\
\hline \multicolumn{8}{|l|}{ Demographic variables } \\
\hline$\%$ male+ & $39.2(36.0-42.6)$ & $52.0(46.0-58.0)$ & $56.9(50.0-63.6)$ & $53.1(46.3-59.7)$ & $0.60(0.45-0.79)^{* * *}$ & $1.54(0.96-2.48)$ & $1.10(0.64-1.89)$ \\
\hline Median age (IQR) & $62(54-71)$ & $56(46-65)$ & $53(43-60)$ & $54(45-62)$ & $0.96(0.95-0.97)^{* * *}$ & $1.06(1.04-1.09)^{* * *}$ & $1.04(1.02-1.07)^{* *}$ \\
\hline$\%$ completed year $10+$ & $81.0(78.1-83.5)$ & $85.2(80.5-89.0)$ & $88.6(83.4-92.3)$ & $89.2(84.2-92.7)$ & $1.36(0.93-1.98)$ & $0.48(0.25-0.91)^{*}$ & $0.34(0.17-0.68)^{* *}$ \\
\hline$\%$ Income below AUD $400+$ & $60.0(56.6-63.3)$ & $54.2(48.2-60.1)$ & $50.5(43.6-57.4)$ & $54.5(47.7-61.1)$ & $0.79(0.60-1.04)$ & $1.39(0.86-2.42)$ & $1.03(0.59-1.77)$ \\
\hline$\%$ unemployed/not in labour force & $39.5(36.2-42.9)$ & $49.8(43.9-55.8)$ & $55.4(48.5-62.2)$ & $54.0(47.2-60.6)$ & $1.51(1.15-2.00)^{* *}$ & $0.54(0.34-0.88)^{*}$ & $0.55(0.31-0.95)^{*}$ \\
\hline$\%$ married/defacto + & $55.2(51.7-58.5)$ & $49.4(43.5-55.4)$ & $46.0(39.2-53.0)$ & $46.0(39.4-52.8)$ & $0.79(0.60-1.05)$ & $1.42(0.88-2.29)$ & 1.94 (1.11-3.39)* \\
\hline
\end{tabular}

** includes meth/amphetamine, cannabis, cocaine, ecstasy, hallucinogenics, heroin. + from baseline interview + Did not meet criteria for DSM-IV ICD-10, ICD-11 dependence and DSM-5 opioid use disorder, \# based on sample of 1,035. OME-Oral morphine equivalents, $\mathrm{mg} /$ day 


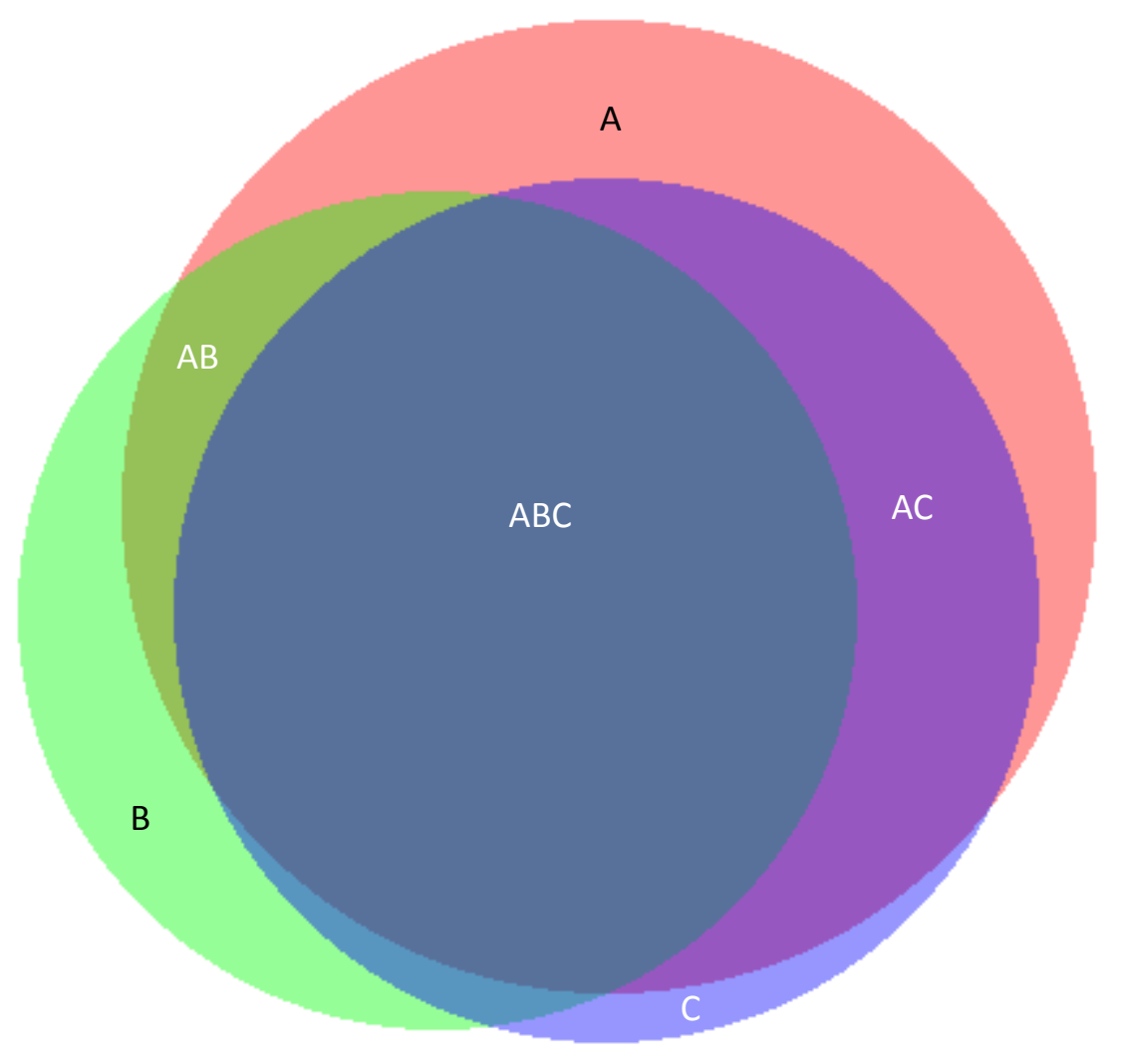

